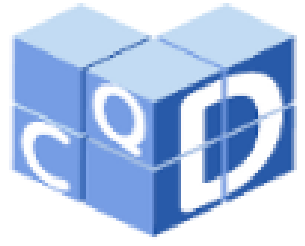

Revista Eletrônica

Paulista de Matemática

ISSN 2316-9664

Volume 10, dez. 2017

Edição Ermac

Marcos Henrique de Paula
Dias da Silva
UNESP - Universidade
Estadual Paulista "Júlio de
Mesquita Filho"
dificildedizer@ gmail.com

\section{A aprendizagem de métodos numéricos com o jogo digital Handles in Scratch 2.0}

The learning of numerical methods with the digital game Handles in Scratch 2.0

\begin{abstract}
Resumo
Os Métodos Numéricos são ferramentas básicas na resolução de problemas científicos modelados matematicamente. Os livros de Cálculo Numérico chegam a abordar minuciosamente alguns exemplos para fins didáticos. Porém, ainda que estes casos estejam ilustrados, contextualizados e até mesmo representados passo-a-passo, não há neles um tratamento lúdico. Abordagens lúdicas permitem que o conteúdo seja aprendido pelo indivíduo ao mesmo tempo que gera um significado sobre esta ação. Assim, criamos um jogo digital com uma dinâmica que usasse Métodos Numéricos para jogar. Sua mecânica envolve controlar um bonequinho pela tela, que armazena rotinas de ações e reage a propriedades lógicas configuráveis pelo jogador durante o jogo. Este artigo analisa a curva de aprendizagem deste jogo, tratando como cada nível pode contribuir no repertório de conhecimentos, habilidades e técnicas ao jogador. Proporcionando neste, um ambiente onde os processos Matemáticos e Computacionais, até então quase totalmente abstratos, sejam tangíveis e ligados a uma narrativa.
\end{abstract}

Palavras-chave: Jogo digital. Curva de aprendizagem. Métodos Numéricos.

\begin{abstract}
Numerical Methods are basic tools in solving mathematically modeled scientific problems. The Numerical Calculus books come to deal with some examples for didactic purposes. However, although these cases are illustrated, contextualized and even represented step-by-step, there is no playful treatment in them. Playful approaches allow the content to be learned by the individual while generating meaning about this action. So, we created a digital game with a dynamics that used Numeric Methods to play. Its mechanics involve controlling a little doll on the screen, which stores action routines and reacts to configurable logical properties by the player during the game. This article analyzes the learning curve of this game, treating how each level can contribute to the repertoire of knowledge, skills and techniques to the player. Providing in this, an environment where the mathematical and computational processes, hitherto almost totally abstract, are tangible and linked to a narrative.
\end{abstract}

Keywords: Digital game. Learning curve. Numerical Methods. 


\section{Introdução}

Os jogos geralmente trazem benefícios únicos para o indivíduo, principalmente porque eles fazem com que sua percepção sobre o assunto ocorra de forma mais aberta, fazendo a aprendizagem mais interativa (ARAÚJO; RIBEIRO; SANTOS, 2012). Embora os jogos estejam na cultura humana desde 3.000 a.C. (HUIZINGA, 1955), não há uma simples definição para este termo. Salen e Zimmerman (2012) apresentam o seguinte quadro relacionando as definições de 8 dos principais autores na área de jogos.

\begin{tabular}{|c|c|c|c|c|c|c|c|c|}
\hline \multicolumn{9}{|c|}{ TABELA 1: Salen e Zimmerman (2012, p. 95). } \\
\hline $\begin{array}{l}\text { Elementos de uma } \\
\text { definição de jogo }\end{array}$ & Parlett & Abt & Huizinga & Caillois & Suits & Crawford & Costikyan & Avedon | Sutton-Smith \\
\hline $\begin{array}{c}\text { Procede de acordo com } \\
\text { regras que limitam os } \\
\text { jogadores }\end{array}$ & $\mathbf{X}$ & $\mathbf{X}$ & $\mathbf{X}$ & $\mathbf{X}$ & $\mathbf{X}$ & $\mathbf{X}$ & & $\mathbf{X}$ \\
\hline Conflito ou competição & $\mathbf{X}$ & & & & & $\mathbf{X}$ & & $\mathbf{X}$ \\
\hline $\begin{array}{l}\text { Orientado a objetivos / } \\
\text { orientado a resultados }\end{array}$ & $\mathbf{X}$ & $\mathbf{X}$ & & & $\mathbf{X}$ & & $\mathbf{X}$ & $\mathbf{X}$ \\
\hline $\begin{array}{c}\text { Atividade, processo ou } \\
\text { evento }\end{array}$ & & $\mathbf{X}$ & & & $\mathbf{X}$ & & & $\mathbf{X}$ \\
\hline $\begin{array}{l}\text { Envolve tomada de } \\
\text { decisões }\end{array}$ & & $\mathbf{X}$ & & & & $\mathbf{X}$ & $\mathbf{X}$ & \\
\hline $\begin{array}{l}\text { Não é sério e } \\
\text { absorvente }\end{array}$ & & & $\mathbf{X}$ & & & & & \\
\hline $\begin{array}{l}\text { Nunca associado ao } \\
\text { ganho material }\end{array}$ & & & $\mathbf{X}$ & $\mathbf{X}$ & & & & \\
\hline $\begin{array}{l}\text { Artificial / Segura / } \\
\text { Fora da vida comum }\end{array}$ & & & $\mathbf{X}$ & $\mathbf{X}$ & & $\mathbf{X}$ & & \\
\hline $\begin{array}{l}\text { Cria grupos sociais } \\
\text { especiais }\end{array}$ & & & $\mathbf{X}$ & & & & & \\
\hline Voluntária & & & & $\mathbf{X}$ & $\mathbf{X}$ & & & $\mathbf{X}$ \\
\hline Incerto & & & & $\mathbf{X}$ & & & & \\
\hline $\begin{array}{c}\text { Faz-de-conta / } \\
\text { Representacional }\end{array}$ & & & & $\mathbf{X}$ & & $\mathbf{X}$ & & \\
\hline Ineficiente & & & & & $\mathbf{X}$ & & & \\
\hline $\begin{array}{l}\text { Sistema de partes / } \\
\text { Recursos e fichas }\end{array}$ & & & & & & $\mathbf{X}$ & $\mathbf{X}$ & \\
\hline Uma forma de arte & & & & & & & $\mathbf{X}$ & \\
\hline
\end{tabular}

Por meio desta tabela, podemos perceber a inconsistência em aderirmos com firmeza a qualquer definição de jogo. Assim, escolhendo nos opor a ideia de jogo como uma atividade imposta pelo educador, tomamos como base neste trabalho as opiniões de Avedon e SuttonSmith (1971), Caillois (2001) e Huizinga (1955), que definem o jogo como atividades voluntárias: 
O jogo é uma atividade livre, ficando conscientemente tomada como "não séria" e exterior à vida habitual, mas ao mesmo tempo capaz de absorver o jogador de maneira intensa e total. É uma atividade desligada de todo e qualquer interesse material, com a qual não se pode obter qualquer lucro. Ela é praticada dentro de seus próprios limites de tempo e espaço de acordo com regras fixas e de uma maneira ordenada. Promove a formação de agrupamentos sociais, que tendem a se cercar de sigilo e sublinhar a sua diferença em relação ao mundo comum, por disfarce ou outros meios. (HUIZINGA, 1955, p. 13)

De acordo com Avedon e Sutton-Smith (1971): “Jogos são um exercício de sistemas de controle voluntário, em que há uma competição entre forças, limitadas por regras para produzir um desequilíbrio."

Jogos são atividades: livres. A interação lúdica não é obrigatória; se fosse, perderia de uma só vez sua qualidade atrativa e alegre como diversão. separadas. Circunscrita dentro dos limites de espaço e tempo, definida e fixada antecipadamente. incertas. $O$ curso da qual não pode ser determinado, nem o resultado obtido previamente e alguma margem para as inovações deixadas para a iniciativa do jogador. improdutivas. Não cria bens, riqueza, nem elementos novos de qualquer espécie; e, com exceção da troca de bens entre os jogadores, termina em uma situação idêntica à que prevalecia no início do jogo. Regidas por regras. Sob convenções que suspendem as leis ordinárias e no momento, estabelecem uma nova legislação, que conta sozinha. Que fazem-de-conta. Acompanhado por uma consciência especial de uma segunda realidade ou fantasia livre, como em oposição à vida real. (CAILLOIS, 2001, p. 9-10)

No caso dos jogos digitais, estes não diferem dos jogos não digitais. Porém há quatro características segundo Salen e Zimmerman (2012) que resumem as qualidades especiais dos jogos digitais. Estas características também estão presentes nos jogos não digitais, mas nos jogos digitais, em geral, estas são incorporadas de forma mais robusta:

Interatividade imediata, mas restrita: um feedback imediato, interativo. Projetando sistemas de ações e resultados, onde o jogo responde perfeitamente à entrada de um jogador. Porém, restrita ao espaço de possibilidades suportado pela modelagem do jogo.

Manipulação da informação: Os gráficos e o áudio não são o único tipo de informação que um jogo digital manipula. Cada aspecto de seu software pode ser considerado como informação.

Sistemas complexos e automatizados: $\mathrm{Na}$ maioria dos jogos não digitais, os jogadores têm de fazer avançar a partida a cada passo, através da manipulação das peças ou comportando-se de acordo com as instruções explícitas descritas pelas regras. Em um jogo digital, o software pode automatizar esses procedimentos e fazer o jogo avançar sem a entrada direta de um jogador.

Comunicação em rede: Os jogos digitais oferecem a capacidade de se comunicar por longas distâncias e partilhar uma variedade de espaços sociais com muitos outros participantes. (SALEN; ZIMMERMAN, 2012, p. 103 - 107)

Em se tratando de jogos como uma ferramenta da aprendizagem, os matemáticos por exemplo desde muitos séculos atrás utilizam os jogos como formas de explicar propriedades ou como problemas a serem investigados, por exemplo, o "jogo dos 15", que pode ser usado para tratar tópicos da álgebra de grupos (PETKOVIC, 2009). Já na visão de James P. Gee (2009), o que um jogo digital costuma ensinar aos jogadores, é apenas como jogá-lo. E isso é algo positivo, pois o jogo sempre carrega algum conteúdo, o qual é aprendido pelos jogadores à medida que jogam e às vezes como requisito para jogar. Uma característica proveniente de sua Manipulação das informações, que como a designer Karen Sideman apontou, aprender as regras do jogo enquanto ele está sendo jogado; torna a descoberta do caminho no qual o jogo opera parte da brincadeira do jogo (SALEN; ZIMMERMAN, 2012, p. 104). 
Da mesma forma, a tecnologia que tornou os jogos digitais viáveis, também viabilizou o uso do Cálculo Numérico, trazendo em contrapartida mais investimentos na construção de Métodos Numéricos para a resolução de problemas, que até antes demandavam grande esforço humano ou eram inviáveis de serem resolvidos. Métodos Numéricos podem ser entendidos como algoritmos que envolvem apenas um sistema de operações elementares dadas a priori, utilizadas um número finito de vezes e que construirão todo o processo de cálculo envolvido. Já o Cálculo Numérico é um campo da Matemática que trata do desenvolvimento de Métodos Numéricos para a resolução aproximada de problemas que podem ser representados por um modelo matemático (CLÁUDIO; JUSSARA, 2000).

Este artigo apresenta um jogo digital com o seguinte conceito inicial: Como o jogador poderia usar Métodos Numéricos para jogar? O conceito inicial de um jogo é uma pergunta passada à equipe de desenvolvimento como um problema a ser resolvido (CHANDLER, 2012).

\section{Estrutura do jogo}

Mattar (2010) defende que as maneiras tradicionais de ensino, eficazes ainda aos imigrantes digitais, não mais se adequam aos nativos digitais. Pois estes, que nasceram ou cresceram na era da tecnologia, desconhecendo vários aspectos da era analógica (PRENSKY, 2012), percebem e aprendem sobre o mundo de um modo diferenciado, compartilhando semelhanças com o processo de evolução que ocorre nos jogos do gênero Adventure, onde o jogador se fortalece conforme supera os desafios na aventura. Este gênero tem como foco a resolução de problemas, a reunião de itens específicos e/ou a administração de recursos e/ou serviços no jogo (ROGERS, 2012).

O projeto New Media Literacies (NML) pesquisa as habilidades e competências necessárias para que os jovens possam participar adequadamente do mundo de hoje. A maioria destas habilidades tem sido muito pouco ensinada nas escolas e muito mais praticada pelos jovens em momentos de lazer, como jogando videogames (MATTAR, 2010).

\subsection{Dinâmicas de base}

Inicialmente tratamos de desenvolver problemas que viriam a servir de espinha dorsal para o jogo. Utilizamos como molde para o jogo ações que poderiam ser realizadas em um software de planilha eletrônica. A dinâmica destes problemas era selecionar números específicos de uma coluna $\mathrm{N}$ números inteiros escolhidos aleatoriamente entre 0 e 99 , sendo $\mathrm{N}$ um número que vai aumentando a medida que o usuário avança. A dificuldade nestes problemas, além do valor de $\mathrm{N}$ aumentar, estava no requisito para a solução do problema.

Um processo de resolução geral envolveria passar pelos $\mathrm{N}$ números um condicional atribuindo 1 se a condição para solução do problema é verdadeira, e 0 se é falsa. Feito isto, podemos reordenar a coluna de 0 's e 1's do maior para o menor, vinculada à coluna de números inteiros entre 0 e 99 . Isto nos dará primeiramente todos os números que cumprem a condição verdade seguidos de todos aqueles que a descumprem.

A construção dos condicionais neste caso seria o desafio real ao usuário destes problemas, visto que no momento que ele Compreende, Estabelece o plano e Executa uma resolução análoga àquela do parágrafo anterior, os demais problemas passam a exigir apenas o Retrospecto deste problema. Ou seja, como construir um condicional que seja verdadeiro somente a todos os números corretos do problema?

Uma dinâmica também possível para este mesmo tipo de problema seria organizar os números corretos em ordem crescente ou decrescente. Assim, ao invés de construir um novo 
condicional que verifique se é verdadeiro e atribua um valor único em relação a sua ordenação, poderíamos reaproveitar todo o processo anterior de seleção, e apenas nestes aplicar uma ordenação.

Outra dinâmica viável para esta espécie de problemas é a associação nominal a dois ou mais números. Assim, cada nome ou índice, possui atribuído a ele vários números. Determinar quais nomes ou índices cumprem com as condições pré-estabelecidas pelo problema seria uma espécie de desafio, que exigiria do usuário algumas manipulações, simplificando as informações e variáveis às condições de verdadeiras ou falsas, de acordo com o problema.

O interessante em explorar uma série de problemas desta categoria é a facilidade com que os mesmos podem ser generalizados como casos análogos aos anteriores. Assim, ainda que um usuário resolva um problema de modo pouco eficiente, à medida que ele vai repetindo o processo, pode otimizar certas etapas ou perceber algumas redundâncias nos seus procedimentos, tornando sua solução melhor e consequentemente melhorando sua habilidade de resolver problemas com o auxílio do computador.

\subsection{Linguagem Scratch 2.0}

Investimos nas dinâmicas propostas para o jogo também visando suportar dos jogadores uma aproximação, aos ambientes de Game Design. Construindo-o em uma linguagem de programação aberta e acessível, por conta da crítica de James Dunnigan, designer de jogos de guerras digitais e não digitais, sobre como os jogos digitais construídos em linguagens fechadas e pouco acessíveis prejudica a autonomia de aprendizagem e senso crítico do jogador:

\footnotetext{
Embora os jogos de guerra para computador tenham muitas vantagens sobre os jogos manuais, eles tinham uma desvantagem importante para os designers de jogos. Os jogos de computador não revelam seu funcionamento interno. Sendo uma vantagem dos jogos de papel que o jogador sabe por que as coisas estão acontecendo de certa forma no jogo. Apesar do trabalho e esforço necessário para percorrer todo o domínio de regras e tabelas de probabilidades nestes jogos, o jogador consegue modificar as regras do jogo e as tabelas de probabilidade. Fazendo isto, muitos jogadores acabam por transformar-se em designers de jogos. No caso destes jogos para computador, o jogador é incapaz de compreender o procedimento que leva aos resultados do jogo (DUNNIGAN, 2000, p. xii).
}

Assim, aderimos ao Scratch 2.0, por ser uma linguagem de programação visual voltada para educação, que foi desenvolvida pelo Lifelong Kindergarten Group do M.I.T. (Massachusetts Institute of Technology). Com mais de 14 milhões de usuários registrados e 17 milhões de projetos compartilhados. Sendo usado em escolas ao redor do mundo como forma de introduzir o básico da programação de computadores para crianças. Mesmo fora das escolas, crianças e adultos ganham um entendimento dos funcionamentos da ciência da computação. Sua plataforma permite criar, editar versões paralelas de projetos e colaborar com projetos de outros usuários. Disponível em mais de 70 idiomas, seus projetos compartilhados são abertos até mesmo para usuários não registrados e podem ser acessados de modo offline ou online usando navegador (LIFELONG KINDERGARTEN GROUP, 2017; OUAHBI et al, 2015).

A respeito da própria complexidade computacional desta linguagem, consideramos o Scratch uma linguagem propícia a ser investida na produção deste jogo, pelas seguintes razões: (LIFELONG KINDERGARTEN GROUP, 2017)

a) O Scratch 2.0 é Turing completo.

b) É principalmente conduzido por eventos. 
c) Seja ou não orientado a objetos, a programação é debatida na comunidade.

d) O Scratch 2.0 possui variáveis e listas para o armazenamento de dados, e os arrays podem ser replicados.

e) O Scratch 2.0 não é atômico em repetição, embora isso possa ser simulado com a programação do quadro único.

f) O Scratch 2.0 faz procedimentos de suporte e recursão.

g) O Scratch 2.0 possui muitas regras de lançamento simplificadas. Os dados não são, no entanto, de primeira classe - você não pode ter listas, sprites ou procedimentos de primeira classe (lambda).

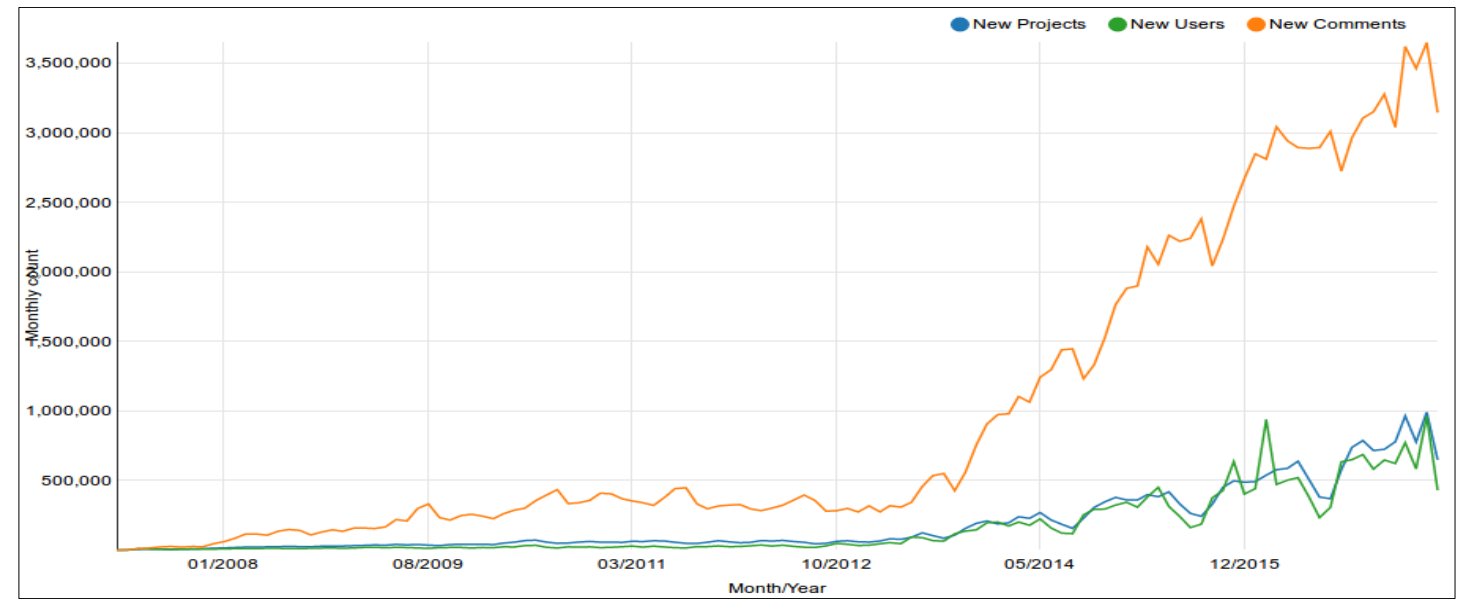

Figura 1: projetos e usuários (LIFELONG KINDERGARTEN GROUP, 2017)

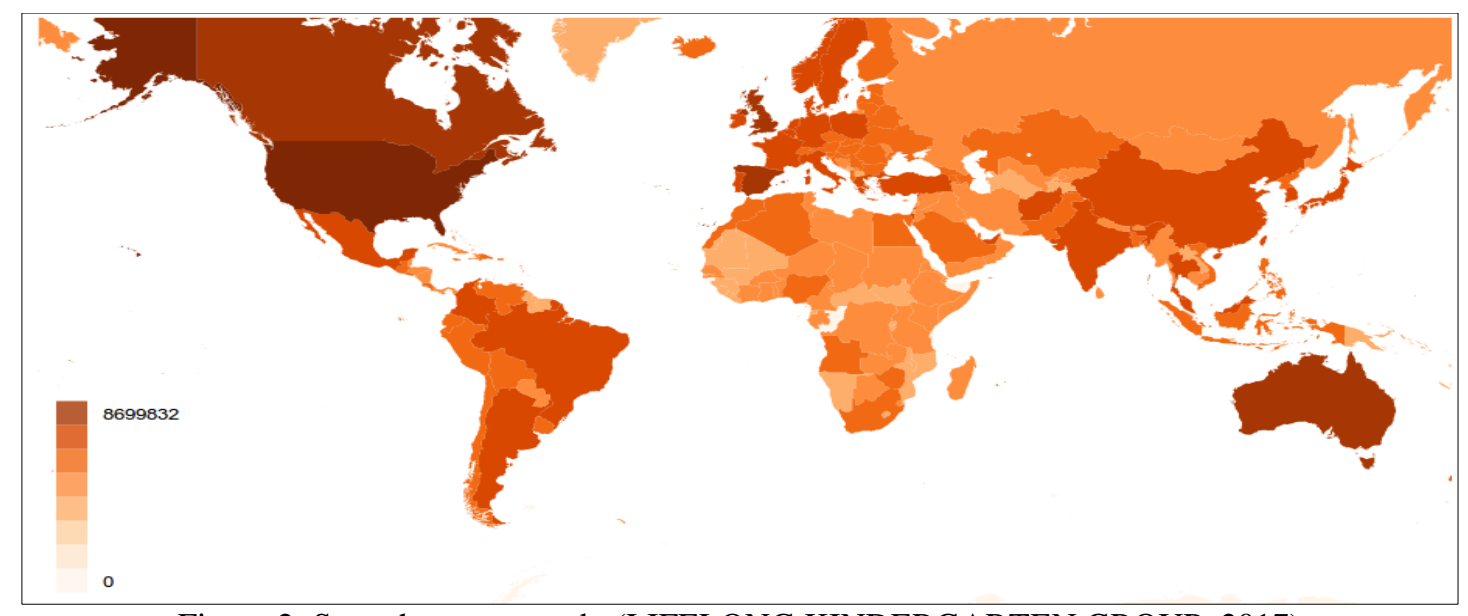

Figura 2: Scratchers no mundo (LIFELONG KINDERGARTEN GROUP, 2017) 


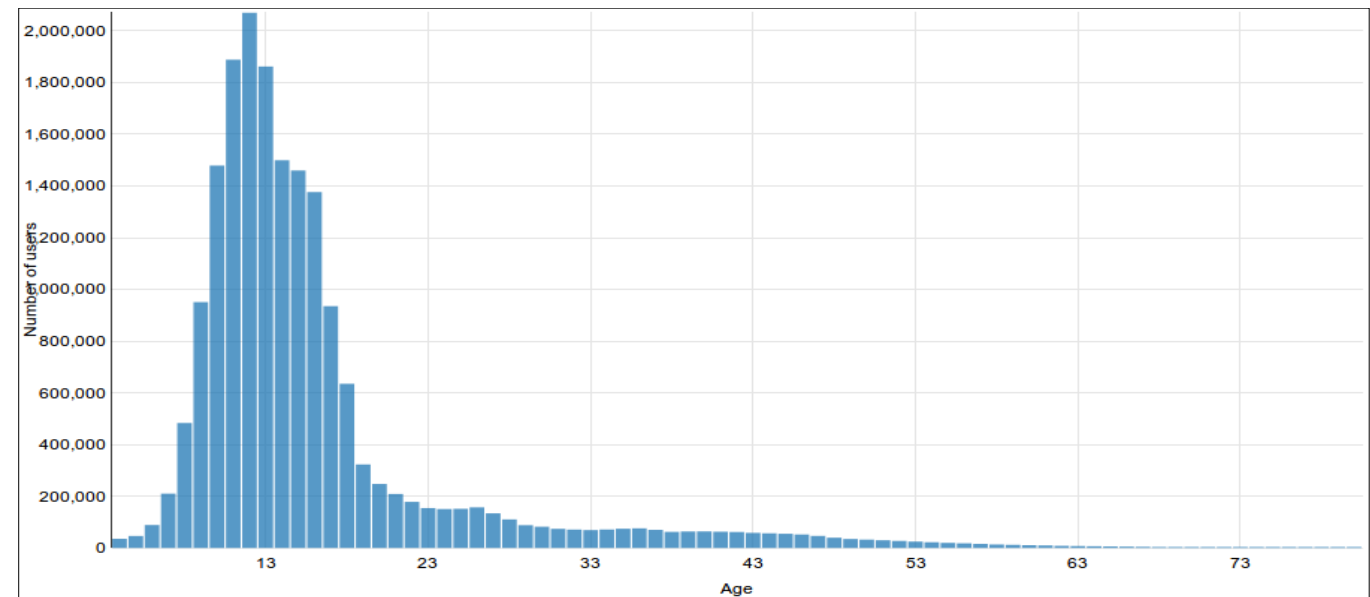

Figura 3: Distribuição dos usuários por idade (LIFELONG KINDERGARTEN GROUP, 2017)

\subsection{Game Design}

Game Design é o processo de projeto de qualquer jogo, onde são definidas ou estabelecidas as características do jogo. Schell (2010) define Game Design como o ato de decidir como um jogo deve ser. Já para Rouse (2005), o Game Design é o que determina a forma e as escolhas que o jogador será capaz de fazer no jogo e quais ramificações essas escolhas terão sobre o resto do jogo, os critérios de ganho e perda, como o usuário será capaz de controlar o jogo.

Dessa forma, com a intenção de torná-lo um bom jogo (competitivo aos inúmeros jogos online gratuitos disponíveis na internet), consultamos livros-guia de Game Design bemconceituados em parte do processo de tomada de decisão. Mas o princípio orientador para a evolução deste jogo foi através do Game Design Iterativo, um processo de design baseado em jogar. Com ênfase em testes práticos com protótipos, o Game Design Iterativo é um método no qual as decisões de design são obtidas da experiência dos jogadores com o jogo ainda em fase de desenvolvimento. O protótipo é reproduzido, avaliado, ajustado e reproduzido novamente, afetando as sucessivas versões do jogo. Este é um processo cíclico que alterna entre prototipagem, teste, avaliação e refinamento. Esta é uma forma de produção bastante utilizada pelos Game Designers, porque não é possível antecipar plenamente o relacionamento do jogador com o jogo, apenas com o conhecimento prévio e expectativas que levam à definição de requisitos e documentação, etapas que antecedem a construção do jogo, pois a interação com o jogo sempre supera seus criadores, especialmente se o design do jogo é incomum ou experimental (SALEN; ZIMMERMAN, 2012). Assim, por meio das experiências obtidas nos testes que ocorreram no processo de desenvolvimento, chegamos ao seguinte jogo:

\subsection{Short Game Design Document}

O Short Game Design Document é uma ferramenta textual-teórica, com características de Game Design Document (GDD), concebido a partir da investigação de diversos modelos de GDD e outros métodos de documentação, para fazer parte do processo de desenvolvimento de um jogo de pequeno porte (MOTTA; TRIGUEIRO JUNIOR, 2013).

O Game Design Document é um modelo de documento que se assemelha a um plano de negócios do jogo, determinando metas, especificando detalhes técnicos que deverão ser 
observados. O intuito é que com este documento, seja possível (junto às habilidades equivalentes) construir o mesmo jogo descrito (ROGERS, 2012).

Significado do nome Handles in Scratch 2.0: Handles significa manejar ou maçanetas, associado ao jogo no sentido de arrastar e manejar operações matemáticas. Scratch significa rabiscar, rascunhar, associando à ideia do jogador poder experimentar o jogo sem medo de errar, até aprender. Scratch 2.0 é a linguagem de programação desenvolvida afim de que crianças aprendam programação, e na qual o jogo foi feito, este nome no título facilita as buscas do jogo pelo Google. Por uma questão de simplicidade linguística, nos referiremos a ele neste artigo apenas como Handles.

$\mathrm{Na}$ tela do jogo por onde o personagem consegue se mover, a princípio surgem números que podem variar de 0 a 29. Para segurá-los, o valor associado ao personagem precisa ser um divisor do número que ele está tocando. Os desafios do jogo envolvem levar os objetos corretos (no início do jogo estes objetos são números, depois passam a ser bolinhos) até a máquina, de modo que quando não há mais destes objetos, o jogador avançaria de nível. Inserir um objeto errado na máquina reinicia o nível. Nesse aspecto, as missões dão ao jogador uma condição a ser respeitada.

História do jogo: Amanda é uma garota esperta e achou um aplicativo que promete aprender como resolve qualquer problema. Ansiosa com a ideia, ela quer te testar (exato, você é o aplicativo e terá que aprender o que Amanda pedir). Ela tentará coisas simples a princípio, mas conforme for se animando, vai complicar as lições, mandará um monte de informações misturadas para você encontrar o que ela quer. Em resumo, essa menina vai atazanar sua vida e brigará com você para que aprenda.

Personagem do jogador: $O$ jogador controla um boneco de palitinho e pode mudar o adorno dele a qualquer momento, o que não afeta suas habilidades, porém a diferença no tamanho do personagem provocada pelo adorno pode facilitar na hora de agarrar objetos.

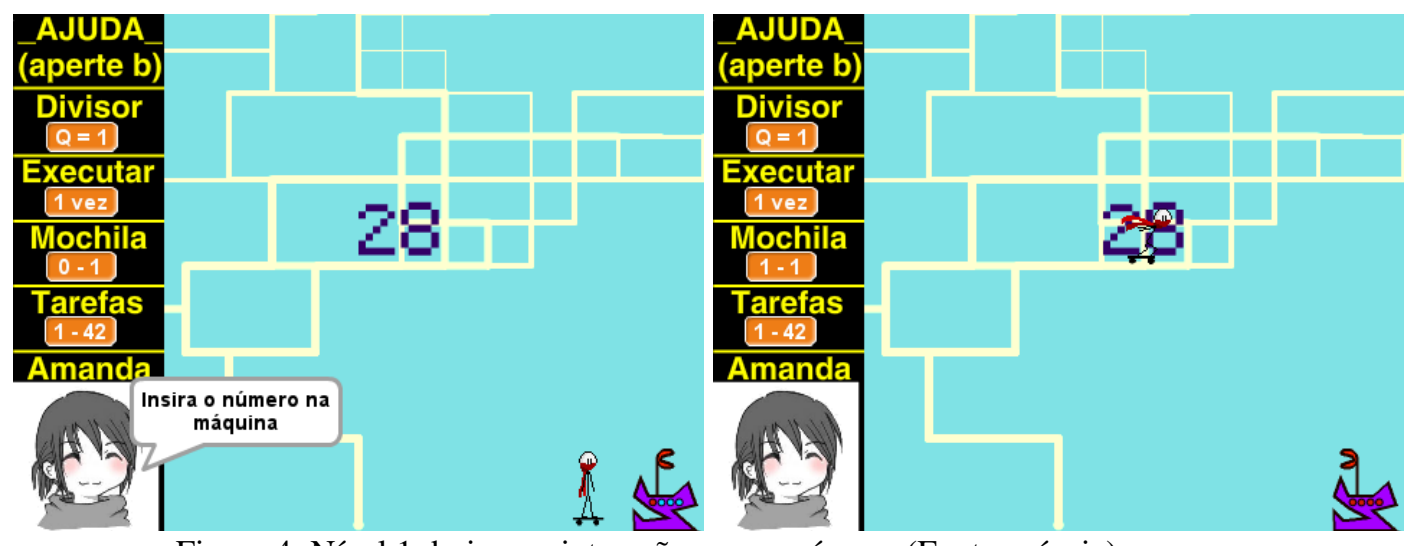

Figura 4: Nível 1 do jogo e interação com o número (Fonte própria)

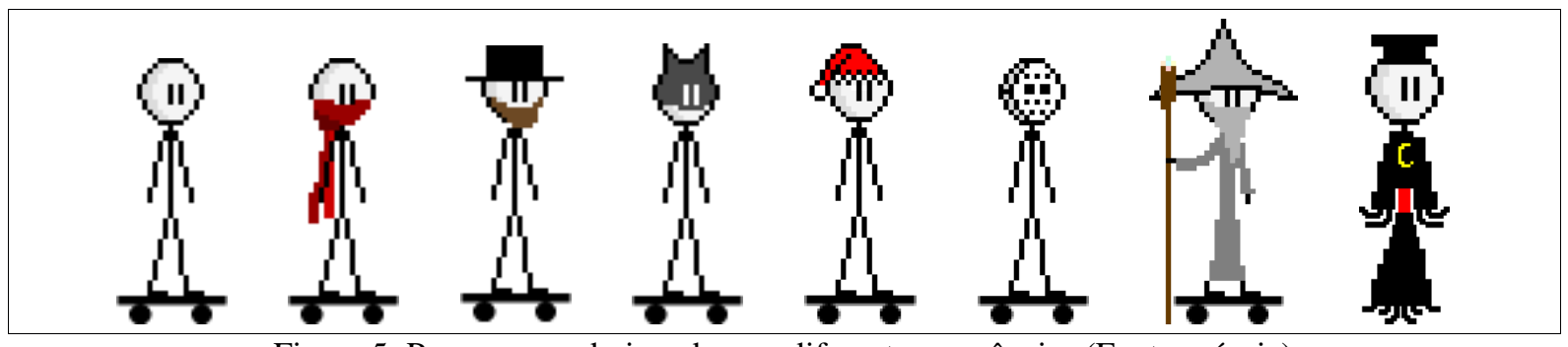

Figura 5: Personagem do jogador em diferentes aparências (Fonte própria) 
TABELA 2: relação de comandos do teclado e funções no jogo (Fonte própria)

\begin{tabular}{|c|c|}
\hline$\rightarrow$ & Move o boneco para a direita \\
\hline$\leftarrow$ & Move o boneco para a esquerda \\
\hline$\uparrow$ & Move o boneco para cima \\
\hline$\downarrow$ & Move o boneco para baixo \\
\hline$Z$ & Insere um objeto que esteja tocando no aparelho ou no instrumento auxiliar \\
\hline$X$ & Começa a gravar os movimentos/Para de executar a gravação \\
\hline$C$ & Começa a executar a gravação/Para de gravar os movimentos \\
\hline$V$ & Troca o adorno do boneco \\
\hline$B$ & Acessa a tela de instruções do jogo \\
\hline$N$ & Amanda diz ao jogador o objetivo da tarefa atual \\
\hline$M$ & Muda a tela de instruções \\
\hline$\rightarrow+Z$ & Adiciona 1 no valor de "Q"/Adiciona 1 no valor de "Mochila" \\
\hline$\leftarrow+Z$ & Reduz 1 no valor de "Q"/Adiciona 1 no valor de "Mochila" \\
\hline$\uparrow+Z$ & Adiciona 1 no número de vezes que a gravação será executada \\
\hline$\downarrow+Z$ & Reduz 1 no número de vezes que a gravação será executada \\
\hline
\end{tabular}

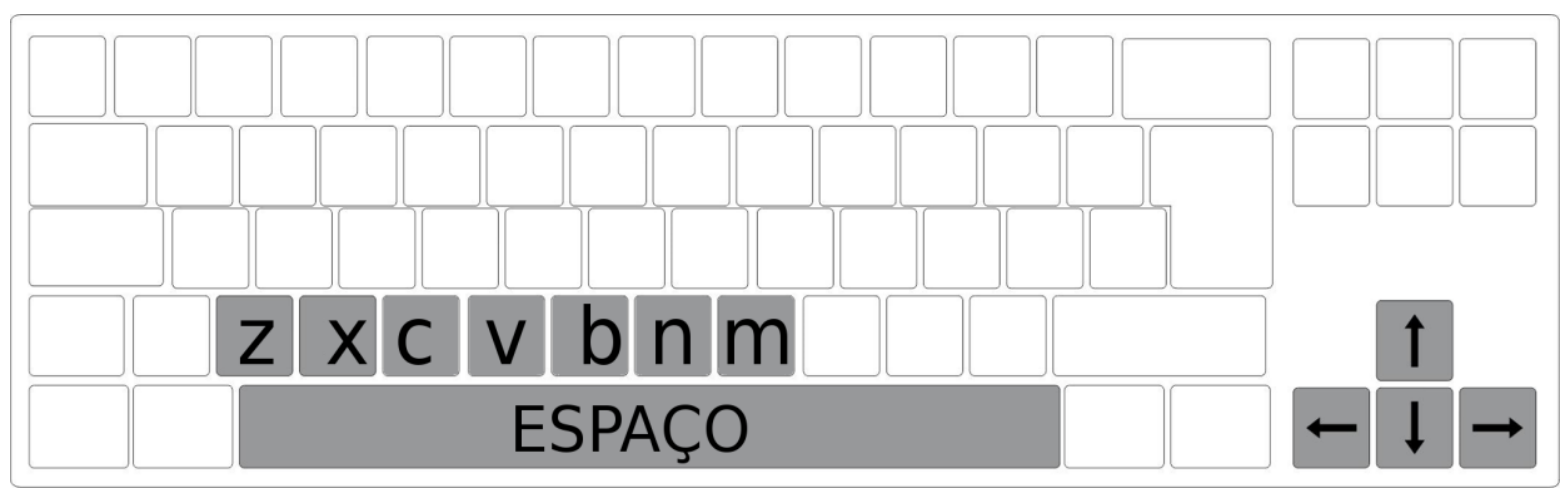

Figura 6: Teclas úteis em referência com a tecla Espaço (Fonte própria)

\subsection{Roteiro completo}

Nível 1: O personagem se move com os direcionais do teclado (as setinhas). Você deve controlar o personagem até o número desejado (quando tocar no número, ele ficará grudado no personagem) e levá-lo até a máquina (aquela coisa se movendo no canto inferior direito). Quando o número estiver tocando a máquina, você aperta $\mathrm{Z}$ para inseri-lo.

Nível 2 - 7: Existem obstáculos de números errados entre você e o número certo. Um jeito de alcançá-los é passando pelos extremos da tela (ao avançar pela direita, você surge do extremo esquerdo da tela, análogo ao avançar para baixo, em que você surge no extremo superior da tela). Um jeito mais fácil de passar estes níveis é indo direto até o número desejado e voltar para a máquina. Perceba que todos os números obstáculos são "1". 1 é um número bastante fino, assim você consegue, mesmo segurando-o, deixar apenas o número desejado tocando a máquina e inseri-lo, apertando $\mathrm{Z}$ para passar de nível (se o 1 estiver em contato com a máquina, você reiniciará este nível). Uma dica é errar de propósito até que o 
número que devemos levar tenha 2 dígitos, o que facilitará muito deixar que apenas ele esteja em contato com a máquina.

Nível 8 - 12: Os números desejados estão agora cercados de números errados e mais grossos que o "1". Ao segurar $\mathrm{Z}$ e apertar para direita ou para esquerda nos direcionais (as setinhas), alteramos o valor "Q" localizado na barra de informações do lado esquerdo da tela. Acima do valor "Q", está escrito Divisor, pois a função do "Q" é determinar quais números grudarão no personagem. Isso funciona da seguinte maneira: se o número que o personagem toca é divisível por "Q", então ele fica grudado no personagem (até que venhamos a alterar o "Q" de modo que esse número não seja mais divisível). O esquema para passar estes níveis é determinar o valor de "Q" como o próprio valor desejado ou um múltiplo exclusivo apenas daqueles valores desejados (se a missão envolve levar os múltiplos de 13, troque "Q" por 13).

Nível 13: Começamos este nível com um 0 bem em cima do personagem. Neste jogo não há um comando que simplesmente solte os números grudados no personagem. Mas, se "Q" não for um divisor de 0 , por exemplo, então o soltaremos. Aqui o único jeito de soltar o 0 é mudando "Q" para 0, pois divisão por 0 é algo impossível. Logo, nenhum número grudará no personagem quando "Q" for igual à 0 .

Nível 14 - 19: Nesses níveis os números desejados estão espaçados por números errados. Em alguns casos conseguimos pegar todos os números desejados diretamente, mudando "Q" para o próprio número, ou escolhendo um múltiplo que seja comum a todos. Porém, há outros casos onde conseguimos pegar apenas os números errados diretamente, sendo os desejados sem nenhum divisor único (ou seja, se você os pega, estará pegando números errados também). A estratégia nessa situação é pegar primeiro todos os errados, levá-los a um local isolado da tela, soltá-los e depois pegar os números desejados sem nenhum obstáculo no caminho.

Níveis 20 e 21: Nesses níveis precisamos pegar ou os "0" ou aqueles que são diferentes de "0". Para pegar os "0" basta selecionar um valor para "Q" superior à todos os outros números da tela (como 30, por exemplo), assim apenas o "0" ficará grudado. Para agarrar aqueles que são diferentes de "0", agarre primeiro todos os "0", coloque-os no canto e pegue os demais números.

A partir do nível 22: Todos os números deixam de ser visivelmente distinguíveis. Embora pareçam figuras estranhas, pensem que eles reagem igualmente aos números dos outros níveis.

Nível 22 e 23: Imagine que os números estão na tela espalhados, precisamos pegar múltiplos de números específicos. Basta trocar o "Q" por estes múltiplos e percorrer a tela agarrando-os.

Nível 24: Nesse nível devemos levar os números 27 e 29 para a máquina. O problema é que não podemos colocar "Q" igual a 27 ou 29, pois se houver algum "0" no caminho, o pegaremos também. A estratégia para este nível é percorrer a tela toda recolhendo os "0" (mude "Q" para 30). Então você solta os "0" em um local isolado (cuidado para não esquecer onde os colocou), e passa o restante da tela com "Q" igual à 27, leva-os até a máquina, e depois com "Q" igual à 29 e leve-os até a máquina.

Nível 25: Similar ao nível 24, mas além do 0, precisamos recolher o número 28 também. Para isso, percorra a tela com "Q" igual à 28 , você agarrará os "0" e os "28" ao mesmo tempo. Após isolá-los, percorra o restante da tela com "Q" igual à 14 e leve-os até a máquina, e depois com "Q" igual à 15 e leve-os até a máquina.

Nível 26 - 30: Nesses níveis a ordem com que os números são inseridos na máquina é importante. Para isso recolha todos os números, isole os "0" mudando "Q" para 30. Com os demais números, selecione o conjunto dos desejados (se são múltiplos de 5, mude "Q" para 5, se são pares, mude "Q" para 2, se são ímpares, isole os pares e fique com o restante). Então 
comece pelo maior valor deste múltiplo, agarrando-os e levando-os até a máquina. A cada processo, reduza do "Q" o valor deste múltiplo (se for múltiplo de 5, a cada iteração, reduza 5 do "Q", se forem pares ou ímpares, reduza a cada iteração 2 do "Q"). Ao final de todos os números inseridos, se não passou de nível ainda, insira o 0 que permaneceu isolado (pois 0 é múltiplo de todos os números).

Nível 31: Neste nível precisamos levar apenas os 1 até a máquina. O problema aqui é que "Q" igual a 1 agarrará todos os números, e não apenas o 1. Agarre todos os números e então comece a puxar para fora deste montinho os números primos entre 2 e 29 (se você não lembra, eles são: $2 ; 3 ; 5 ; 7 ; 11 ; 13 ; 17 ; 19 ; 23 ; 29)$. Ao final, mude o "Q" para 0 , soltando qualquer coisa que você ainda esteja agarrando. Retorne ao que sobrou (ou seja, apenas o 1) e leve-o para a máquina.

Nível 32 - 35: Nestes níveis deixamos de ter números e passamos a ter bolinhos. Também ganhamos um instrumento para nos auxiliar, o escâner (no canto inferior esquerdo da tela). Além disso, a habilidade de trocar o "Q" deixa de funcionar, e passa a controlar o valor da "Mochila". A Mochila funciona da seguinte maneira: o valor da direita é o total de objetos que podem ser segurados, e o valor da esquerda é a quantidade de objetos que estão sendo segurados. O escâner funciona da seguinte maneira, quando ao menos um bolinho contaminado está em contato com o escâner e apertamos $\mathrm{Z}$, sua luz muda de cor por um segundo e todos os bolinhos que estão em contato com o escâner são deslocados à direita do escâner. O processo para solucionar estes níveis é recolher todos os objetos, então levar metade deles até o escâner para verificação. Se o escâner detectar que o bolinho contaminado está nesse grupo, ignore definitivamente o outro grupo. Se o escâner não detectar que o bolinho contaminado está nesse grupo, ignore-o definitivamente (isolando-o na tela) e passe a trabalhar apenas com o outro grupo. Repetindo o processo de pegar sempre metade do total restante de bolinhos e testá-lo para decidir com qual grupo prosseguir o procedimento, resolvemos rapidamente estes desafios.

Níveis 36 e 37: O método utilizado nos níveis 32 até 36 se aplica nestes níveis também, mas precisamos repeti-lo pelo número de bolinhos contaminados que existem no nível.

Nível 38 - 40: Nestes níveis perdemos o escâner, mas ganhamos o instrumento auxiliar: a balança (localizada no centro inferior da tela). A balança funciona da seguinte maneira: ela compara o peso entre o prato esquerdo e o direito. No lado que estiver mais pesado, os bolinhos ficam mais afastados do centro, no lado que estiver mais leve, os bolinhos ficam próximos ao centro. Se ambos os lados tiverem pesos iguais, os bolinhos de ambos os lados ficam próximos ao centro. A estratégia para estes níveis é agrupar todos os bolinhos, então levar $1 / 3$ deles até um dos pratos, o outro $1 / 3$ para o outro prato. Se um dos lados estiver mais pesado, ignoramos aquele $1 / 3$ que não colocamos na balança e aquele $1 / 3$ do lado mais leve, e repetimos o procedimento até que haja apenas 1 bolinho. Se ambos os lados derem pesos iguais, ignoramos estes $2 / 3$ que comparamos e repetimos o procedimento apenas com aquele $1 / 3$ que não comparamos.

Níveis 41 e 42: Nestes níveis há mais que um bolinho mais pesado. Compará-los do mesmo jeito que fizemos nos níveis anteriores não nos dá certeza de nada. Nesse caso, a estratégia seria inicialmente comparar dois bolinhos. Se um deles tiver peso diferente, leve o mais pesado até a máquina e comece a comparar os demais bolinhos com aquele bolinho que sabemos não ser o mais pesado. Porém, se o peso deles for igual, pode ser que os dois sejam mais pesados que os demais. Para determinarmos se não são, precisamos pegar um número maior de bolinhos do que a quantidade de bolinhos mais pesados que existem naquele nível (se existem 2 bolinhos mais pesados no nível, então precisamos pegar além dos dois que estão na balança, mais um bolinho, se existem 3 bolinhos mais pesados, então precisamos pegar mais dois bolinhos...). Então, mantemos um bolinho de um dos lados da balança e 
comparamos com os outros que trouxemos. Se estes forem realmente os mais pesados, leve-os para a máquina. Se não, coloque um bolinho que não seja mais pesado em um dos lados da balança e comece a comparar um a um com este bolinho. Quando obter um bolinho mais pesado, leve-o para a máquina, quando a comparação mostrar que são de mesmo peso, ignore este bolinho isolando-o na tela e faça o procedimento com o próximo.

Após completar as 42 tarefas propostas pela Amanda, é apresentado ao jogador uma parabenização. Nela, Amanda expressa bastante entusiasmo. Entretanto, o jogo pergunta se a partir de agora o jogador gostaria de editá-lo, indicando onde clicar para isso. A mensagem também anuncia a página do jogo em uma rede social, como uma oportunidade de comentar e manter-se atualizado sobre o jogo.

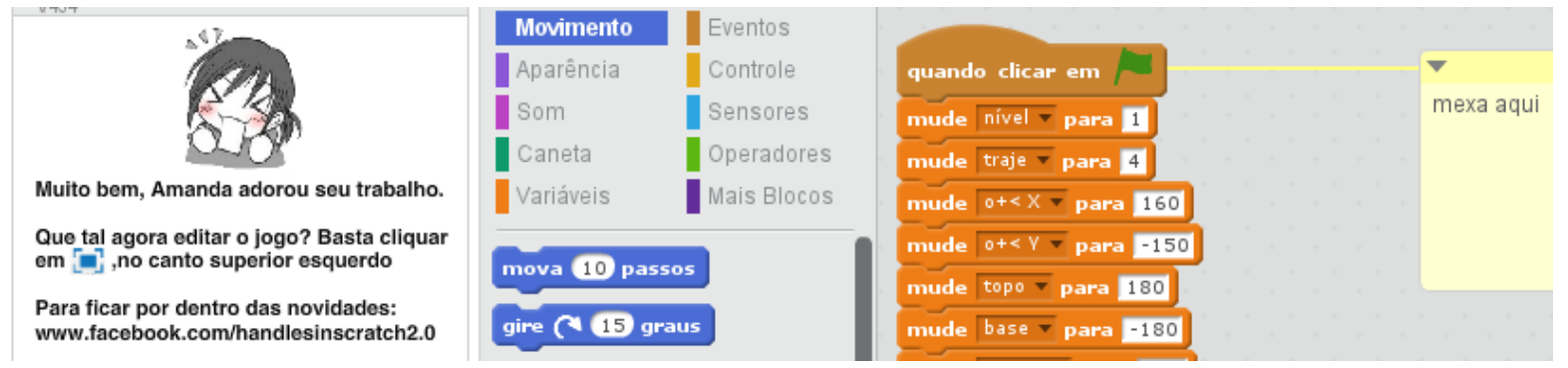

Figura 7: Software do jogo aberto para edição (Fonte própria).

A curva de aprendizagem deste jogo, como pode ser vista na descrição acima, foi desenvolvida para que o jogador adquira até o final, habilidades necessárias para planejar e executar diversos algoritmos computacionais.

\section{Métodos Numéricos no jogo}

Silva (2017) apresenta uma reflexão sobre como alguns Métodos Numéricos (busca linear, bissecção, trissecção) são presentes e comparáveis em eficiência ou praticidade dentro do contexto do jogo Handles. As seções seguintes abordam essas mesmas reflexões, porém fazendo uso de contextos mais atualizados do próprio jogo Handles.

\subsection{Busca linear}

A busca linear ou sequencial é um método de busca que verifica elemento por elemento dentro de uma lista. Seu principal uso ocorre em situações onde não há ordem entre os elementos ou quando a lista é pequena, já que sua implementação é bastante simples (WIRTH, 1989). Este vem a ser o primeiro dos métodos que o jogador encontrará, pois precisará verificar os objetos para selecionar os adequados à missão. Se bem escolhida a forma de verificá-los, a lista várias vezes se torna pequena.

$\mathrm{Na}$ tela do jogo, por onde o personagem consegue se mover, surgem objetos ao início ou reinício de cada nível. Quando estes objetos são números, eles podem variar de 0 a 29. Para segurá-los a seguinte condição deve ser verificada:

1. O valor associado ao personagem é um divisor do número que ele tenta segurar?

A partir do $22^{\circ}$ nível, os números se tornam indistinguíveis visualmente, exigindo que o jogador determine os números corretos a partir de suas propriedades de divisão, como por exemplo:

1. O 15 não é um par (isto evita que o 0 seja segurado) e é divisível por 15.

2. O 14 não é divisível por 4 (isto evita que o 0 e o 28 sejam segurados) e é divisível por 14. 
Do $25^{\circ}$ ao $30^{\circ}$ nível, a ordem dos números passa a ser relevante, exigindo que o jogador ordene do maior ao menor, todos os números que compartilham a propriedade pedida na missão, aparecendo assim o algoritmo de busca linear. Embora seja um processo lento, nesta etapa do jogo é esperado que o jogador produza rotinas de repetição, usando as propriedades de programação do personagem, colocando-o para verificar cada possibilidade automaticamente. Nesta situação, nosso interesse é que o jogador perceba como o recurso computacional pode facilitar a busca pela solução.

Entretanto, no nível $31^{\circ}$ colocamos ao jogador a missão de levar apenas os números 1 para o aparelho. Nessa situação, o jogador pode utilizar a abordagem automática ou manual, respectivamente:

1. Isolar todos os números que possuem divisores variando de 2 até 29. Exige 28 verificações.

2. Isolar todos os números que possuem divisores primos. Exige 10 verificações.

Este vem a ser um caso onde o jogador tem a alternativa manual mais eficiente que a automatizada.
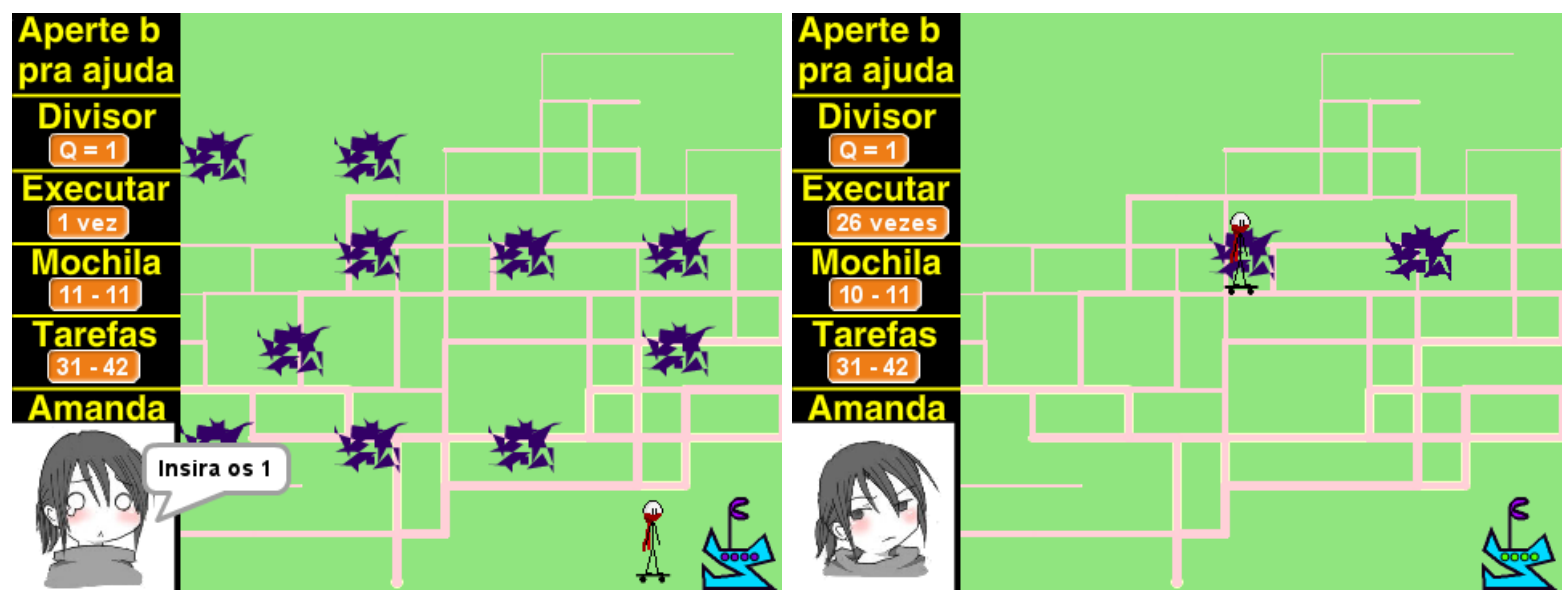

Figura 8: Situação de selecionar os 1 e após abordagem automatizada (Fonte própria).

\subsection{Busca linear versus método da bissecção}

Embora a busca linear seja um método simples, intuitivo e em diversos casos, necessário, quando há uma ordem entre os elementos e o tamanho da lista aumenta, seu uso é substituído por métodos mais eficientes como a bissecção (WIRTH, 1989).

A partir do $32^{\circ}$ nível, todos os problemas passam a envolver bolinhos. Dessa forma para segurar um objeto, passamos a verificar apenas se a carga total do personagem é menor que seu total. Assim, o personagem deixa de atuar como um verificador e, com isso, acrescentamos à mecânica do jogo e de acordo com o nível, um instrumento externo ao personagem, que possibilite cumprir a missão.

Até o $36^{\circ}$ nível, a missão é relativa a colocar no aparelho apenas os bolinhos contaminados. Para descobrir quando um bolinho está contaminado, inserimos no jogo o instrumento "escâner", que mostra uma luz vermelha quando ao menos um dos bolinhos em contato com ele está contaminado, em seguida o escâner empurra todos os bolinhos para a sua direita. Estes níveis podem ser resolvidos a partir da verificação automática de bolinho por bolinho. Entretanto, como podemos reunir os bolinhos uniformemente, acima de um intervalo fechado da reta, e cada vez que verificarmos um destes intervalos, descobriremos se o bolinho contaminado se encontra lá ou não. O que enquadra nosso problema na condição do Teorema 
de Bolzano, permitindo que apliquemos o método da bissecção, com o qual, a cada etapa eliminamos até metade do total de bolinhos.

Teorema de Bolzano. Se $y=f(x)$ é uma função contínua e muda de sinal no intervalo [a, b], então existe pelo menos um ponto $x \in[a, b]$ tal que $f(x)=0$ (CUNHA, 2003, p. 74).

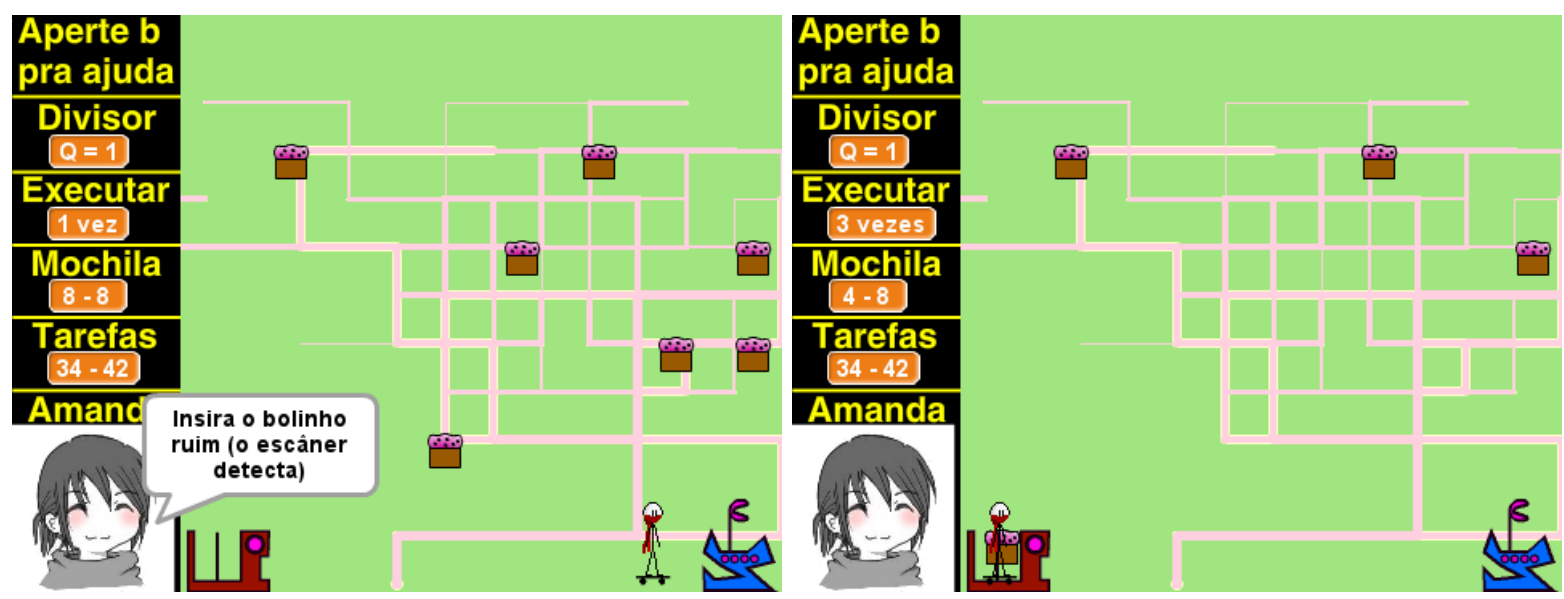

Figura 8: Situações do escaner checando o estado dos bolinhos (Fonte própria).

\subsection{Método da trissecção}

A partir do $37^{\circ}$ nível surgem desafios envolvendo o peso dos bolinhos. Assim o "escâner" desaparece e no centro da tela surge outro instrumento, uma "balança de pratos". O lado que estiver mais pesado passará os bolinhos para o prato mais afastado do seu eixo. Nesse tipo de situação apenas um bolinho possui peso diferente dos demais. Este nível pode ser resolvido a partir da verificação automática de bolinho por bolinho permanecendo, na balança o bolinho mais pesado. Mas, podemos reunir os bolinhos uniformemente acima de um intervalo fechado da reta e cada vez que verificarmos dois intervalos de mesmo tamanho, descobriremos em qual intervalo o bolinho mais pesado se encontra, se enquadrando na condição do Teorema de Bolzano. Assim, podemos usar o método da bissecção.

Contudo, esta situação permite uma abordagem melhor, utilizando o método da trissecção. Já que podemos dividir nosso total de bolinhos em 3 e comparar 2/3 deles, se a balança cair para um dos lados, descartamos o $1 / 3$ do outro lado da balança e o $1 / 3$ do total de bolinhos que não foi colocado na comparação. Se a balança ficar em equilíbrio, descartamos os $2 / 3$ de bolinhos que foram colocados na balança. Assim, a cada etapa eliminaríamos 2/3 do total de bolinhos.

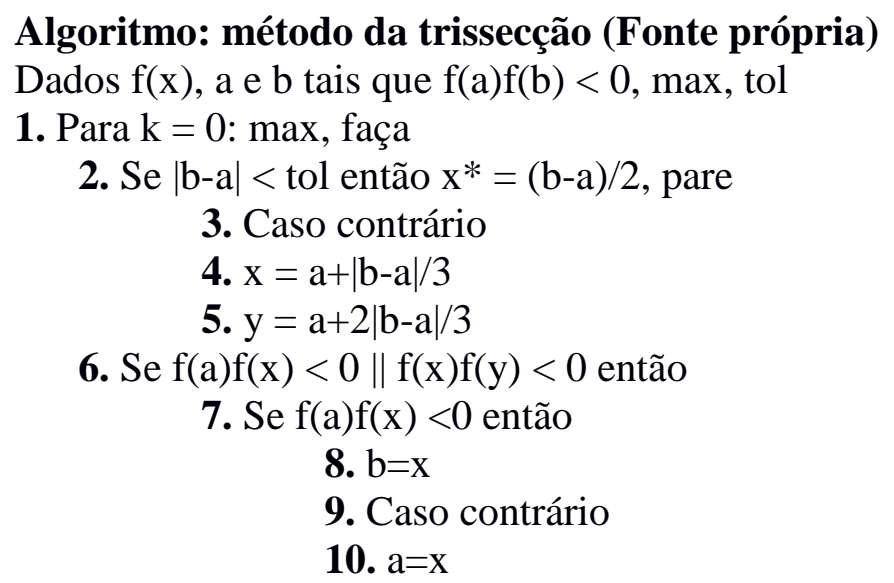




\section{1. $b=y$}

12. Caso contrário

13. $a=y$

Embora computacionalmente este método não seja tão interessante, pois seu custo computacional (devido ao passo 6 do algoritmo) é superior ao da bissecção, o uso do algoritmo da trissecção é comum em alguns desafios matemáticos, como quando precisamos descobrir com apenas duas pesagens qual dentre 9 bolas idênticas é a única com um peso diferente. Visto que o procedimento manual permite a realização do passo 6 do algoritmo como uma única ação. Assim, no caso do jogo, onde a movimentação dos objetos ocorre de modo similar ao procedimento manual, o uso do método da trissecção também se faz mais eficiente do que o método da bissecção.

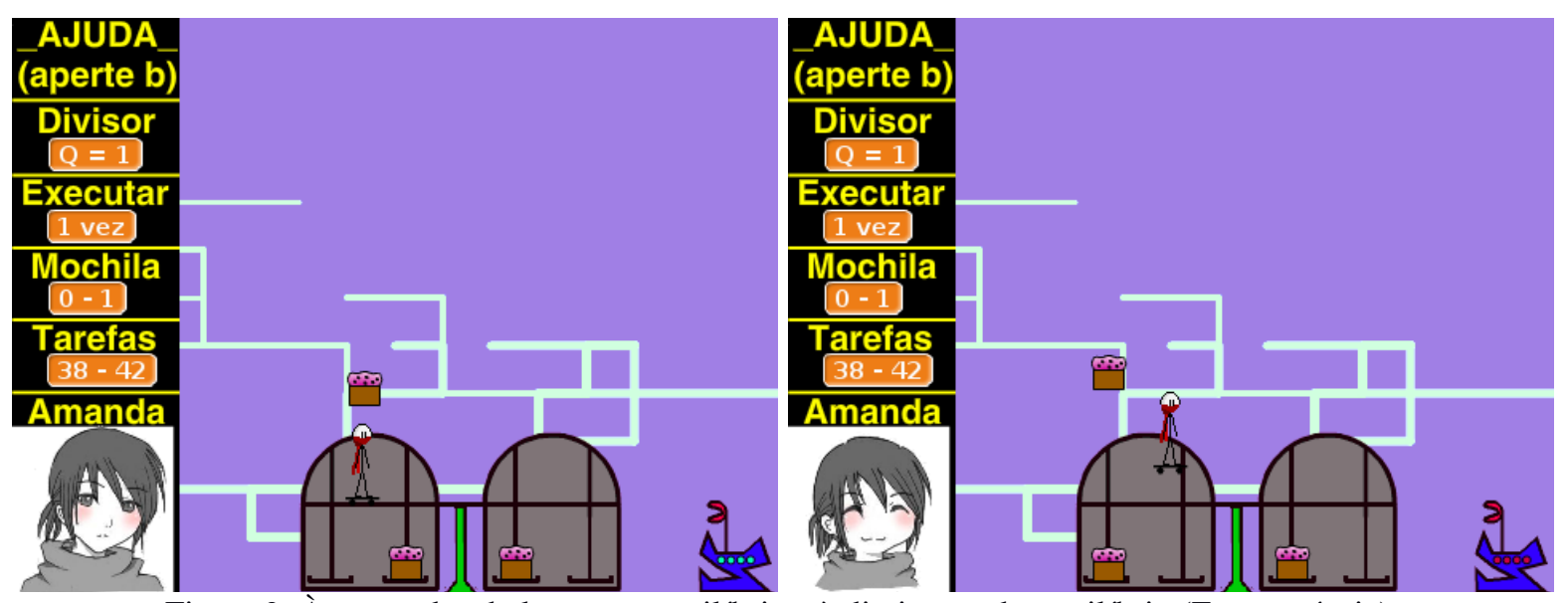

Figura 9: À esquerda a balança em equilíbrio e à direita em desequilíbrio (Fonte própria).

\section{Conclusão}

Essa percepção sobre a diferença entre os métodos é nosso maior interesse em explorar no jogo, pois uma das qualidades essenciais aos métodos numéricos é sua eficiência (CLÁUDIO; JUSSARA, 2000). Como exemplo temos a Regra de Cramer, que é ensinada no Ensino Básico para a resolução de um sistema com $\mathrm{N}$ equações e $\mathrm{N}$ incógnitas e envolve o cálculo de $\mathrm{N}+1$ determinantes de ordem $\mathrm{N}$. E também o método da Eliminação de Gauss, que consiste em transformar o sistema linear original num sistema linear equivalente com a matriz de coeficientes triangular superior, tendo assim, uma resolução imediata (RUGGIERO; LOPES, 1996).

TABELA 3: Comparando eficiência entre algoritmos (CLÁUDIO; JUSSARA, 2000, p. 23).

\begin{tabular}{|c|c|c|c|}
\hline $\begin{array}{c}\text { Cramer } \\
\text { (determinantes pela } \\
\text { definição) }\end{array}$ & $2.5 \mathrm{~s}$ & 3.4 dias & 20 bilhões de anos \\
\hline $\begin{array}{c}\text { Cramer } \\
\text { (determinantes por } \\
\text { Laplace) }\end{array}$ & $0.4 \mathrm{~s}$ & 6 minutos & 5 meses \\
\hline Eliminação de Gauss & $36 \mathrm{~ms}$ & $0.22 \mathrm{~s}$ & $1.5 \mathrm{~s}$ \\
\hline
\end{tabular}


No caso do jogo, frente às situações onde vários métodos são possíveis, cabe ao jogador julgar qual melhor se enquadra para solucionar seu problema, tendo em conta tanto a praticidade de sua construção, quanto sua eficiência. Abaixo apresentamos a comparação de quantas verificações são necessárias no jogo para problemas de pesar os bolinhos, onde apenas um tem um peso diferente, sendo o $\mathrm{N}$ o número de bolinhos iniciais.

TABELA 4: Comparação de eficiência entre métodos com a balança no jogo (Fonte própria)

\begin{tabular}{|c|c|c|c|}
\hline & $\mathrm{N}=21$ & $\mathrm{~N}=201$ & $\mathrm{~N}=2001$ \\
\hline Busca linear & 20 verificações & 200 verificações & 2000 verificações \\
\hline Método da bissecção & 5 verificações & 15 verificações & 45 verificações \\
\hline Método da trissecção & 3 verificações & 5 verificações & 7 verificações \\
\hline
\end{tabular}

Este jogo foi produzido para que os jogadores desenvolvam o chamado pensamento computacional, definido por Wing (2006), como o conjunto de habilidades e atitudes que cientistas da computação utilizam no tratamento de problemas, para que estes possam ser resolvidos por computadores. A importância do pensamento computacional se estende além dos cientistas da computação, uma vez que este é o pensamento que usamos para encontrar o melhor método de resolver um problema, tendo como recursos a astúcia e imaginação humana junto com a velocidade e capacidade de armazenamento do computador.

Nesse sentido, até mesmo alguns livros de cálculo numérico, pouco abordam a praticidade de um método contra sua eficiência, pois, em casos simples, resolver um problema manualmente é conveniente e não exige a implementação de um método. Entretanto, em outros casos, podemos isolar a solução em algumas propriedades e aplicar bons métodos numéricos. Contudo, sempre haverá situações onde a força bruta será necessária, isto é, a exigência de um processo exaustivo para a obtenção da resposta. Fazer com que o jogador adquira a percepção sobre como um problema pode ser resolvido e se autoavaliar a cerca de sua eficiência, são nossos objetivos com este jogo.

\section{Referências}

ARAÚJO, N. M. S.; RIBEIRO, F. R.; SANTOS, S. F. dos. Jogos pedagógicos e responsividade: ludicidade, compreensão leitora e aprendizagem. Bakhtiniana, Rev. Estud. Discurso, v.7, n. 1, p. 4-23, 2012.

AVEDON, E. M.; SUTTON-SMITH, B. The study of games. Nova York: John Wiley \& Sons, 1971.

CAILLOIS, R. Man, play, and games. Urbana: University of Illinois Press, 2001.

CHANDLER, H. M. Manual de produção de jogos digitais. 2. ed. Porto Alegre: Bookman, 2012.

CLÁUDIO, D. M.; JUSSARA, M. M. Cálculo numérico computacional: teoria e prática. 3. ed. São Paulo: Atlas, 2000.

CUNHA, M. C. C. Métodos numéricos. 2. ed. rev. e ampl. Campinas: UNICAMP, 2003. 
DUNNIGAN, J. F. Wargames handbook: how to play and design commecial and professional wargames. 3. ed. San Jose: Writers Club Press, 2000.

GEE, J. P. Bons videogames e boa aprendizagem. Florianópolis: Revista Perspectiva, v. 27 n. 1, p. 167-178, 2009.

HUIZINGA, J. Homo ludens: a study of the play element in culture. Boston: Beacon Press, 1955.

LIFELONG KINDERGARTEN GROUP. Scratch. [Cambridge]: MIT Media Lab, 2017. Disponível em: <https://wiki.scratch.mit.edu/wiki/Scratch>. Acesso em: 12 jul. 2017.

MATTAR, J. Games em educação: como os nativos digitais aprendem. São Paulo: Pearson Prentice Hall, 2010.

MOTTA, R. L.; TRIGUEIRO JUNIOR, J. Short game design document (SGDD): documento de game design aplicado a jogos de pequeno porte e advergames: um estudo de caso do advergame Rockergirl Bikeway. In: SIMPÓSIO BRASILEIRO DE JOGOS E ENTRETENIMENTO DIGITAL, 12., 2013, São Paulo. Proceedings... São Paulo: Universidade Presbiteriana Mackenzie, 2013. p. 115-121. Disponível em: <http://www.sbgames.org/sbgames2013/proceedings/artedesign/15-dt-paper_SGDD.pdf>. Acesso em: 9 nov. 2017.

OUAHBI, I. et al. Learning basic programming concepts by creating games with Scratch programming environment. Procedia: Social and Behavioral Sciences, v. 191. p. 1479-1482, 2015.

PETKOVIC, M. S. Famous puzzles of great mathematicians. Providence: American Mathematical Society, 2009.

PRENSKY. M: Aprendizagem baseada em jogos digitais. São Paulo: Senac, 2012.

ROGERS, S. Level up: um guia para o design de grandes jogos. São Paulo: Blucher, 2012.

ROUSE, R. Game design: theory \& practice. 2. ed. Plano: Wordware Publishing, 2005.

RUGGIERO, M. A. G.; LOPES, V. L. R. Cálculo numérico: aspectos teóricos e computacionais. 2. ed. São Paulo: Pearson Makron Books, 1996.

SALEN, K.; ZIMMERMAN, E. Regras do jogo: fundamentos do design de jogos. São Paulo: Blucher, 2012, v. 1.

SCHELL, J. A arte de game design: o livro original. Rio de Janeiro: Campus, 2010.

SILVA, M. H. P. D. Jogo digital para o ensino de métodos numéricos. In: ENCONTRO REGIONAL DE MATEMÁTICA APLICADA E COMPUTACIONAL, 4., 2017, Bauru. Caderno de trabalhos completos e resumos. Bauru: Unesp, Faculdade de Ciências, 2017. p. 170-177. Disponível em: 
$<$ http://www.fc.unesp.br/\#!/departamentos/matematica/eventos2341/ermac/cadesnos-detrabalhos-completos-e-resumos/>. Acesso em: 16 nov. 2017.

WING, J. M. Computational thinking. Commun. ACM, v. 49, n. 3, p. 33-35, 2006.

WIRTH, N. Algoritmos e estruturas de dados. Rio de Janeiro: LTC, 1989.

Artigo recebido em jun. 2017 e aceito em nov. 2017. 